\title{
The International Nature of Intellectual Properties for Timely Economy and Life Quality Evolution
}

\section{Akbar Nikkhah*}

Chief Highly Distinguished Professor, Department of Animal Sciences, Faculty of Agricultural Sciences, University of Zanjan, National Elite Foundation, Iran

\section{Introduction}

This article establishes a pragmatic concept that multinational intellectual properties need to be amalgamated and interevolutionized for life quality to experience real unbiased improvement on a global scale. The intellectual properties that are central to this forum include elite minds, strategies, policies, methodologies and practices that any nation around the global may develop. Based on a main premise of this theory, cooperation (among nations and thoughts) overshadows and embraces the mere foremost competition towards betterment of science education and research, growth of economy, and improvement of life quality standards.

In essence, what applies to a nation in terms of cooperating and collaborating among different sectors and fundamentals towards human growth and development also applies with, at the very least, the same importance - realistically contemplating, with indeed far more significance - to any specific geopolitical region, group, ally, treaty, continent, and certainly to the globe the utmost. In other words, converging the multiple domestic interests into definitive policies for national development ought to be applied globally that means converging multinational perspectives into unified global programs for timely maturity of the entire world. Generating this convergence becomes more crucial when science and education are concerned $[1,2]$. Divergence among nations, particularly in science education and research, may no longer be tolerated in the postmodern era should 'peace and prosperity for all' be the goal to accomplish for any leading economy and pragmatic ideology $[3,4]$.
Philosophically and ultimately, humans will realize that perfection in life quality is in no ways achievable by merely competing against each other's interests that, as history reveals, requires violation of human rights in many ways. Human will discover and learn to compete against egotistical and narcissistic tendencies to overcome the nonintellectual challenges that keep the world from realizing ultimate peace and wealth. Such an optimal pragmatic competition necessitates focusing on and highlighting different common international interests for mind cooperation and moral partnership.

In a nutshell, the only healthiest and most productive expression of competition for further global growth is international cooperation of intellectual properties'. This is what the man will strive for in a populated and limited natural environment.

\section{Acknowledgment}

The Iran's Ministry of Science Research and Technology, National Elite Foundation, and University of Zanjan gratefully thanked for supporting the author's programs of optimizing the new millennium global science education.

\section{References}

1. Nikkhah A (2014) Science of the new times: A circle not a line. Adv Crop Sci Tech 2: e111.

2. Nikkhah A (2011) Elite Science Education Arts of the New Millennium. Lap Lambert Publishing, Germany.

3. Nikkhah M, Nikkhah A (2011) Optimizing academic education: philosophies for creative quality lives. Creative Education 2: 458-460.

4. Nikkhah A (2011) Science education of the new millennium: mentorship arts for creative lives. Creative Education 2: 341-345.

*Corresponding author: Akbar Nikkhah, Chief Highly Distinguished Professor Department of Animal Sciences, Faculty of Agricultural Sciences, University of Zanjan, National Elite Foundation, Iran, Tel: +98-24-33052801; E-mail: anikkha@yahoo.com, nikkhah@znu.ac.ir

Received January 15, 2015; Accepted January 17, 2015; Published January 25 2015

Citation: Nikkhah A (2015) The International Nature of Intellectual Properties for Timely Economy and Life Quality Evolution. Intel Prop Rights 3: 136. doi:10.4172/2375-4516.1000136

Copyright: ( 2015 Nikkhah A. This is an open-access article distributed under the terms of the Creative Commons Attribution License, which permits unrestricted use, distribution, and reproduction in any medium, provided the original author and source are credited. 